\title{
OS DISPLAYS DIGITAIS COMO FERRAMENTA COMUNICACIONAL SUPRAMIDIÁTICA
}

THE DIGITAL DISPLAYS AS A TOOL SUPRA COMMUNICATIONAL MEDIA

\author{
LA PANTALLA DIGITAL COMO HERRAMIENTA SUPRA COMUNICACIONAL DE \\ MEDIOS
}

\author{
Taís Marina Tellaroli \\ Universidade Metodista de São Paulo \\ taistella@hotmail.com
}

Sebastião Carlos Squirra
Umesp
ssquirra@gmail.com

\section{Resumo}

Investiga-se as mudanças comunicativas adotando como conceito de referência o display digital interativo. Com a fusão das tecnologias das mídias audiovisuais com as do computador, surge um supra-suporte que engloba os demais, suas diferentes linguagens e formatos, antes difundidos e consumidos em múltiplos aparelhos. A tecnologia é o principal fator dessa transformação, sendo a informatização o motor central de mudança, na transição do mundo analógico para o digital. A convergência promoveu junção midiática radicalmente confluente sendo que se sugere o termo displays digitais para denominar as fantásticas bases de recepção de produtos comunicativos do mundo moderno, que se tornaram híbridas e multitelas.

Palavras-chave: displays, mídias digitais, tecnologias da comunicação.

\begin{abstract}
It examines the communicative changes adopting as reference the concept of interactive digital display. With the merging of the technologies of audiovisual media with computer, arise an overpower support encompassing all other, their different languages and formats, that was, before disseminated and consumed in multiple devices. Technology is the main factor of this transformation, with the informatization as the central engine of change in the transition from analog to digital world. The convergence promoted by the junction of confluent media suggests the term digital displays to describe these fantastic communicative bases of the modern world, which have become hybrids and multiscreens.
\end{abstract}

Keywords: displays, digital media, communications technology 


\section{Introdução}

Em todos os sentidos, a vida moderna é fortemente definida pelas tecnologias. Amplamente presentes na vida após a industrialização da sociedade, nos tempos atuais estas são altamente eficientes e atualmente são mesmo invisíveis, por terem se tornado digitais. Em nível abrangente, a evolução dos artefatos técnicos adotados pela sociedade é resultado do trabalho de conjuntos diversificados de técnicos, engenheiros, administradores e cientistas e, no caso dos recursos tecnológicos digitais incluem ainda desenvolvedores de software, designers e contingente ampliado de pesquisadores que pensam e desenvolvem produtos que atendam aos desejos da sociedade. Essas mudanças têm como força propulsora a criação do Personal Computer (PC) que, com o surgimento da internet e sua veloz disseminação, a partir de meados dos anos 1990, tornou-se equipamento cada vez mais presente e fundamental em todos os setores da sociedade, tanto nas empresas quanto nas casas das pessoas. O passo seguinte foi dado por Steve Jobs, da Apple, que entendeu que se inaugurava a era de um estilo digital de vida, após observar que a sociedade adotava fortemente os recursos informatizados, pois passaria a ter aparelhos celulares, câmeras digitais, DVDs, entre outros, em casa e na experiência profissional. Por isso ele e outros empresários consideraram a explosão dos dispositivos digitais, tendo o computador como um grande $h u b^{l}$ capaz de acoplar todos os aparelhos periféricos (KAHNEY, 2009, p. 173).

Dessa forma, e pelo perfil de muitos aparatos digitais, constata-se que o território ampliado das tecnologias avança rapidamente e abarca de forma consistente também todas as dimensões do segmento da comunicação. Afinal, há cerca de 20 anos quem poderia imaginar a comunicação móvel, a interatividade, a troca e o compartilhamento de arquivos entre pólos opostos no mundo ou uma biblioteca virtual disponível com todo tipo de conhecimento produzido pelo homem? Tanta inovação em um período tão curto altera consistentemente a sociedade, a economia, a cultura e a vida, enfim. Atinge também a política fazendo-a passar por transformações, como aconteceu quando o atual presidente dos Estados Unidos, Barack

\footnotetext{
${ }^{1} \mathrm{Hub}$ significa concentrador, ou seja, um único aparelho que reúne diversos outros aparelhos.
} 
Obama, utilizou as Redes Sociais ${ }^{2}$, em 2008, para se promover e angariar 500 milhões de dólares pela internet, conforme relata Sueli Bacelar (2010). Dessa forma, o Governo Eletrônico publiciza suas ações e as aplicações dos governantes, também ampliando a cidadania.

\section{A tecnologia e a sociedade}

A tecnologia pode ser definida etimologicamente, segundo a origem latina da palavra, como o "estudo do ofício". Goldemberg (1978, p. 157) a define como sendo "o conjunto de conhecimentos de que uma sociedade dispõe sobre ciências e artes industriais, incluindo os fenômenos sociais e físicos, e a aplicação destes princípios à produção de bens e serviços”. O autor indica que a tecnologia é produzida com um fim objetivo, para ser aplicada em soluções cotidianas. $\mathrm{Na}$ atualidade, tais conhecimentos se materializaram em máquinas em rede que estão em constante evolução. Mas, como sucessão de processos, todas as tecnologias são substituídas em velocidade constante remetendo os equipamentos descartados ao esquecimento quase que instantâneo, como alerta Nicola Nosengo (2008, p. 16) quando este diz que

a despeito do papel central que a tecnologia ocupa em nossa vida, na verdade, nós sabemos pouco do processo de inovação tecnológica através do qual vários artefatos se originaram, se difundem, se modificam no tempo e talvez um dia desapareçam.

Para Nosengo, este incessante processo de descarte e constante substituição cria um conceito novo, criando o que ele chamou de tecnossaurus, ou seja, Dinossauros tecnológicos ${ }^{3}$, indicando mesmo um espaço para o acompanhamento e conhecimento do enorme parque de tecnologias de comunicação extintas ou em vias de extinção ${ }^{4}$.

Andrew Feenberg (1991, p.14) pensa na tecnologia como dimensão da vida humana e não somente como meio técnico desenvolvido ao longo da história. Para ele,

\footnotetext{
${ }^{2}$ Segundo Raquel Recuero (2009, p. 102), sites de Redes Sociais "são os espaços utilizados para a expressão das redes sociais na Internet", softwares que reúnem atores, ou seja, pessoas envolvidas na rede que estabelecem conexões formadas a partir das interações sociais. Estes sistemas permitem a construção de uma "persona" através do perfil, troca de mensagens e a exposição pública de quem participa.

${ }^{3}$ Idem, p. 16

${ }^{4}$ Idem, p. 19, valendo consultar a direção http://www.deadmedia.org.
} 
parto não apenas de uma hipótese sobre a essência do computador, por exemplo, que ele privilegia controles ou comunicações, valores humanistas ou pós-humanistas, mas, de preferência, de uma análise da maneira pela qual tais hipóteses influenciam os próprios agentes, moldando design e uso. $\mathrm{O}$ mundo da tecnologia é o meio dentro do qual os agentes interagem com o computador. Nesse mundo da vida, os processos de interpretação são centrais. Os recursos técnicos não são apenas pré-dados, mas adquirem significado por esses processos. À medida que as redes de computador se desenvolveram, funções de comunicação acabaram sendo introduzidas mais pelos usuários do que tratadas como recursos do médium pelos criadores dos sistemas.

São os usuários, que a partir da exploração e uso contínuo do produto criado, podem informar com maior precisão se aquela tecnologia atende ou não as expectativas e necessidades deles. Todavia, nem sempre as indústrias entendem o momento certo para cada tecnologia que produzem. É o caso do Walkman da Sony, por exemplo, que apesar deste aparelho ter sido símbolo de uma geração, a empresa não acompanhou o desejo dos usuários não permitindo que estes equipamentos tocassem arquivos em MP3, o que a fez perder lugar para o iPod da Apple. No universo de plenas evoluções, os aparatos tecnológicos tornaram-se profundamente onipresentes e muitos são mais do que símbolos da modernidade, pois carregam em si valores de quem os fabrica e de quem os consome, identificando todos em formas de tribos tecnológico-sociais, como as que se vê na atualidade.

Do seu lado, e no caso de mídias massivas, constata-se que o avanço da tecnologia digital, que se tornou online e em tempo real, colide com um momento transitório da mídia televisiva quando esta migra do sistema analógico para o digital. A convergência daí advinda fez com que tais impactos acarretassem um processo de fusão de linguagens e formatos dos meios interagentes, modificando as bases comunicativas consolidadas por mais de 70 anos pela plataforma televisiva. Nestas décadas, enquanto aparelho técnico, a televisão experimentou processo de constante evolução, primeiro quando as transmissões preto-ebranco passaram a ser em cores e, posteriormente, quando o número de canais aumentou fazendo com que os telespectadores passassem a usar o controle remoto. E, em seguida quando foram acoplados ao aparelho televisor alguns dispositivos periféricos, como o videocassete e o videogame, conforme definem Carlos Montez e Valdecir Becker (2005, p.33) em obra específica sobre a TV Digital Brasileira quando estes dizem que

a próxima etapa da evolução tecnológica da TV reside na digitalização de parte da produção, com a introdução de câmeras e ilhas de edição digitais. $\mathrm{O}$ 
passo seguinte foi o da transmissão digital dos fluxos de áudio e vídeo e o uso de set top boxes para receber e decodificar esses fluxos. A fase final de mais essa evolução da TV é a substituição do conjunto TV analógica + set top box por receptores totalmente digitais.

Dessa forma, a análise histórico-tecnológica da mídia revela que é a partir da digitalização que começam a aparecer rumores e expectativas quanto ao futuro da mídia, pois as imagens e sons da TV são transformados em bits", ou seja, "são processados eletronicamente por chips e microprocessadores de última geração que traduzem a imagem animada em códigos numéricos, em milhões de combinações de dígitos binários de informação" (SIQUEIRA, 2008, p. 39), aproximando televisão e computadores. Esse caldo de transformações tecnológicas, que incluía, por exemplo, a plena digitalização da informação, indicava o início de processos de alterações que atingiriam mesmo a identidade midiática no cenário no qual a televisão se encontrava longamente inserida. $\mathrm{O}$ primeiro deles trouxe uma discussão simplória, porém importante e diz respeito à precisão, em si, do próprio termo televisão, indagando se este continuava apropriado para designar a difusão de imagens audiovisuais no furacão tecnológico digital que se presencia, onde todos os processos comunicativos se misturam e estão presentes na mesma base receptiva.

Aponta-se isto, pois hoje as imagens podem ser captadas por infinidades de aparelhos, e podem ser vistas em diversos formatos e tamanhos. Na modernidade, as imagens estão profusamente em displays que poderão estar perto ou longe do consumidor, no trabalho, nos meios coletivos de transporte ou em casa, em aparelhos estáticos ou portáteis. Kerckhove (1995, p. 89) defende que, quando a televisão entra na era digital, ela automaticamente passa a evoluir para o status do computador, quando este ganha o poder da comunicação a distância (assim como o telefone) herda um grande legado da TV, que é de ter acesso a "um grande número de pessoas ao mesmo tempo, em tempo real”.

\section{Nova mídia na era da convergência}

A convergência tecnológica que se materializa nas mãos dos consumidores é resultado da evolução dos meios de comunicação em plataformas cada vez mais envolventes, interativas

\footnotetext{
${ }^{5} \mathrm{Na}$ informática, o bit é a menor unidade de informação possível de ser transmitida ou armazenada, assumindo apenas dois valores, 0 ou 1 .
} 
e completas. Fruto da amigabilidade dos atracamentos tecnológicos, as facilidades digitais tiveram processos tecnológicos unificados e hoje permitem que a partir de um aparelho seja possível se comunicar com outras pessoas (com imagens dos dialogantes), ler notícias (em tempo real), tirar fotos (e enviá-las imediatamente), fazer filmagens (e expô-las nos sites de compartilhamento), trocar informações (individualmente ou nas redes sociais), assistir a conteúdos televisivos (das emissoras ou dos anônimos produtores de documentários), e por ai caminha a humanidade. Enfim, um único meio reúne centenas de tecnologias inventadas pelo homem, explicitando que essa junção dos processos de comunicação dinamiza a experiência humana como nunca na história. E o motor central disso é o computador, que se tornou o elemento que viabiliza esta transformação, onde a televisão, que praticava modelo linear e analógico de transmissão, ao entrar na era digital, é forçada a convergir com a web e se tornar algo diferente. Todavia, para que a convergência tecnológica acontecesse, foi preciso, primeiro, que a mídia se tornasse digital.

O sistema digital é capaz de armazenar quantidades gigantescas de imagens e dados, pode ser randomicamente editado e não depende de um meio geográfico para ser acessado, pois através das redes instaladas tem abrangência mundial. Atualmente todas as bases comunicativas são digitais e a TV, o rádio e a internet mergulharam nesse sistema pela inevitável evolução tecnológica que está disponibilizando todas as mídias nos displays a que todos têm acesso, sejam os aparelhos das TV conectadas, seja na tela dos tablets, nos telefones interativos e inteligentes etc.

A tendência é a da completa migração da tecnologia analógica para a digital devido aos infindáveis benefícios oferecidos por esse sistema, pois entre outros, há melhora na manipulação dos dados que podem ser facilmente processados em computadores. Outra vantagem do sinal digital é a sua representação universal, pois é codificada em sequiências de bits, conforme esclarecem Carlos Montez e Valdecir Becker (2005, p.65), quando dizem que "todos os tipos de informações digitais (inclusive as que não são multimídia) podem ser manipulados, armazenados e transmitidos da mesma forma, usando o mesmo tipo de equipamento".

Com a fusão das tecnologias das mídias audiovisuais e da tecnologia do computador, constata-se que praticamente surge uma nova mídia, realidade constituída em ambiente que está em plena evolução. O teórico Lev Manovich (2000, p. 66), que estudou a linguagem da 
nova mídia, explica que, para definir este ambiente, é preciso entender cinco princípios da tecnologia digital: a representação numérica, modularidade, variablilidade, programabilidade e automação. Indo adiante na questão, Manovich (2000, p. 27) explica que todos os objetos da nova mídia são compostos por códigos digitais e podem ser descritos matematicamente, representados por zeros e uns. A digitalização simplifica a manipulação desses objetos de uma mídia para outra, como por exemplo, quando se transfere um vídeo gravado em uma máquina fotográfica digital para o computador. Além disso, toda mídia digital (com textos, imagens, dados de áudios e vídeos etc.) possui o mesmo código e pode ser exposta em vários dispositivos, como por exemplo, no computador, no aparelho de televisão, num player de vídeo, no celular etc. Na manipulação digital não há perda de qualidade dos dados originais quando o conteúdo é transferido entre as diferentes máquinas, pois todo conteúdo digital possui uma quantidade fixa de informações, que não se alteram com sua operação.

Outra característica da nova mídia é a modularidade, ou seja, o acesso à mídia digital é feito em sistema aleatório (ou randômico) e não linear, como na base analógica. Dessa forma, é possível selecionar exatamente o conteúdo que se quer ver, ou a parte de um material específico, sem ficar restrito à seqüência desses dados. Um site, por exemplo, apresenta objetos separados como imagens, vídeos, links, que estão dispostos na página independentemente e o usuário vai escolher o que acessar (MANOVICH, 2000, p. 140), pulando de um para outro na seqüência desejada. Assim, e superando uma limitação das bases analógicas, no sistema digital, o objeto da nova mídia pode ser infinitamente copiado sem sofrer perdas tanto na qualidade quanto na quantidade de informação estocada. Mas, e talvez uma das mais sedutoras qualidades seja que o padrão digital permite que as mensagens sejam também modificadas, possibilitando que seus temas sejam alterados e ampliados, em sistemas colaborativos, processo impossível no passado. No maior site de vídeos do mundo o YouTube $e^{6}$ - são constantes os vídeos que sofrem alterações, recebendo novas versões feitas pelos internautas.

Por ser digital, a nova mídia é personalizável, uma vez que os usuários podem interferir em sua estrutura e desenvolver novas formas de desempenho para os softwares como é o caso do sistema chamado GNU/Linux. O Linux é software livre e deu início a uma nova forma de criação e disponibilização de sistemas e softwares às pessoas. Com seu código-

\footnotetext{
${ }^{6}<w w w . y o u t u b e . c o m>$.
} 
fonte $^{7}$ disponível abertamente e com livre acesso às pessoas, é possível que cada empresa ou pessoa modele o sistema de acordo com suas necessidades pessoais de uso (MANOVICH, 2000, p. 31). Do seu lado, na automação, a máquina desempenha modelo mais ativo e quando programada pode "tomar decisões" (de fato, estas são ações definidas por um ser humano) agindo a partir do comportamento do usuário, no que induz aos processos da usabilidade homem-máquina que nos leva à inteligência artificial. O Google Search ${ }^{8}$ representa bem essa função quando busca informações publicadas em toda a Internet, define qual grau de relevância cada uma possui e as disponibiliza aos internautas por ordem de importância.

Dentre todas essas características das mídias digitais, definidas por Manovich (2000, p. 66), tem mais uma que se destaca fortemente, pois ele lembra que a nova mídia é interativa. Nesse sentido, esse autor afirma que

\begin{abstract}
A nova mídia é interativa. Em contraste com a mídia tradicional, cuja ordem de apresentação era fixa, o usuário agora pode interagir com um objeto de mídia. No processo de interação, o usuário pode escolher quais os elementos para mostrar ou quais caminhos a seguir, gerando assim um trabalho único. Assim, o usuário se torna co-autor do trabalho ${ }^{9}$ (tradução nossa).
\end{abstract}

Todos os elementos das novas mídias integram, parcialmente, as mídias tradicionais como, por exemplo, a mídia online, a televisão e o jornal impresso. A televisão está em processo de transição do analógico para o digital, e o jornal assume a hibridização de estar na rede em formato digital e, ao mesmo tempo, sendo vendido em formato papel nas bancas de revistas. Mas, no caso da TV, há mais de 15 anos Negroponte $(1995$, p.54) alertava que "se pararmos de pensar no futuro da televisão em termos exclusivamente de alta definição e começarmos a construí-lo em sua forma mais geral - a da irradiação de bits -, a TV se transformará num veículo inteiramente diferente”. A interatividade é uma ferramenta que vai começando aos poucos a ser desenvolvida na televisão, já na Internet é ela que modifica a forma tradicional de comunicação, por isso, quando as mídias agregam novas ferramentas tecnológicas, iniciam mudança nos emissores, no conteúdo apresentado e nos receptores das

\footnotetext{
${ }^{7} \mathrm{O}$ código-fonte detalha o funcionamento e características do software para que possa ser estudado e alterado.

${ }^{8}$ O Google Search é um sistema de busca desenvolvido pelo Google e é considerado um dos mais inteligentes da rede.

9 No original: New media is interactive. In contrast to traditional media where the order of presentation was fixed, the user can now interact with a media object. In the process of interaction the user can choose which elements to display or which paths to follow, thus generating a unique work. Thus the user becomes the coauthor of the work.
} 
mensagens. Negroponte toca em uma questão altamente relevante para o início da discussão da convergência tecnológica quando diz que é preciso pensar na digitalização como fator propulsor da transformação do maior veículo de comunicação do mundo, a televisão. Para este autor, a digitalização potencializa a convergência tecnológica, dando plasticidade e fluidez aos conteúdos que transitam em suportes tecnológicos diferentes.

Na mesma linha, Ithiel de Sola Pool (1983, p. 23), considerado o profeta da convergência por delinear suas implicações no livro Technologies of Freedom trabalha com a "convergência de modos" para definir um processo que torna tanto as fronteiras da comunicação de massa (televisão, rádio, jornais) quanto aquelas ponto-a-ponto (telefone, correio, telégrafo) imprecisas quando estas podem ser oferecidas em diversas formas físicas. Estas são questões importantes. Mas, indo além da questão técnica abordada por Pool e Negroponte, o autor Henry Jenkins (2008, p. 27) relaciona três conceitos para definir a convergência tecnológica: o da convergência dos meios de comunicação, a cultura participativa e a inteligência coletiva. No caso específico do primeiro conceito Jenkins adianta que

\begin{abstract}
por convergência refiro-me ao fluxo de conteúdos através de múltiplos suportes midiáticos, à cooperação entre múltiplos mercados midiáticos e ao comportamento migratório dos públicos dos meios de comunicação, que vão a quase qualquer parte em busca de experiências de entretenimento que desejam. Convergência é uma palavra que consegue definir transformações tecnológicas, mercadológicas, culturais e sociais, dependendo de quem está falando e do que imaginam estar falando.
\end{abstract}

O paradigma da convergência tecnológica coloca os meios de comunicação tradicionais em interessante embate com as novas mídias, pois antigamente as empresas de comunicação centralizavam seus esforços - e atuavam concentradamente - em apenas um segmento comunicacional, ou seja, na mídia rádio, ou na mídia televisão, ou na mídia impressa etc. Assim também procedia o mercado anunciante, que dividia recursos e ação de divulgação observando esses modelos rigidamente formatados para a destinação de investimentos. Do seu lado, e como conseqüência do modelo o público consumidor seguia o mesmo princípio, comprando artefatos e destinando tempo para uma mídia ou outra. Todavia, com o impacto da tecnologia, estes paradigmas estão desmoronando, pois não há mais o muro que separa uma mídia da outra, uma vez que nas bases digitais convergentes, amigáveis e dialogantes do presente, os conteúdos fluem aberta e facilmente entre todas as mídias, 
indistintamente das formas narrativas ou segmentações de outrora. Essa fluidez deixa nas mãos dos usuários a decisão de como e quando consumir o conteúdo já que estes se apresentam de várias maneiras, sendo materializáveis nas plataformas (os displays que falamos antes) audiovisuais que se tenha acesso, no momento da conexão.

Com a fertilidade e dinâmica da convergência, inicialmente muitos autores previam que todos os aparelhos iriam convergir em um único aparelho, mas Jenkins (2008, p. 41) mostra que, na realidade, o hardware está sendo mantido em artefatos próprios sendo que o que converge é essencialmente o conteúdo. $\mathrm{O}$ autor pondera que o que acontece é que os novos aparelhos proliferam em inúmeros modelos e muitos deles, por serem de companhias concorrentes, são personalizados visando fazer com o consumidor adquira o aparelho de determinada empresa. Mas, como os conteúdos (nos filmes, nas ligações telefônicas com imagens, na internet etc.) transitam entre as máquinas, estes ultrapassam as limitações das plataformas das distintas indústrias. Os tablets $^{10}$ são um exemplo dessa robusta tendência. $\mathrm{O}$ iPad da empresa Apple representa o caso de aparelho tecnológico que depois do seu lançamento em janeiro de 2010, se mostrou um campeão de vendas substituindo aos poucos os netbooks ${ }^{11}$ que era a tendência tecnológica daquele momento. Segundo Evans (2010, online), mesmo sendo a primeira versão do aparelho, $72 \%$ dos consumidores estão muito felizes com a compra, $23 \%$ contentes e apenas $1 \%$ dos que compraram o iPad não gostaram da aquisição ${ }^{12}$. O comportamento do mercado e a profusão de aparelhos neste sistema revelam que a tecnologia veio para ficar.

Os telefones celulares passam por uma crise de identidade quando além de exercerem a função a que se destinam, que é a de telefone, são usados como câmeras fotográficas, filmadoras, internet, videogame, etc. tornando-se um aparelho multimídia. Pelo acréscimo de funções, Nicola Nosengo chama tal aparato tecnológico de videotelefonia ${ }^{13}$, pois superaram a habilidade da transmissão de sons no formato reduzido de comunicação dirigida entre duas pessoas para transmitir imagens, acessar a rede, consultar banco, ler livro, ver televisão, realizar vídeo conferências etc. Por isso, entende-se que enquanto os aparelhos se multiplicam, o conteúdo se prolifera na mesma proporção. E estas alterações do processo

\footnotetext{
${ }^{10}$ Um tablet é um computador pessoal em formato de prancheta sensível ao toque.

${ }^{11}$ Netbooks são mini notebooks.

${ }^{12}$ EVANS, Johnny. Microsoft admite que iPad está 'matando' o mercado de netbooks. Disponível em: <http://www.fndc.org.br/internas.php?p=noticias\&cont_key=615140>. Acesso em: 10/11/2010.

${ }^{13}$ Idem, p. 13
} 
comunicativo fazem com que o impacto seja sentido por todas as empresas midiáticas, quer estas estejam no país e fora dele. Pressionadas pelo comportamento das tecnologias e pela sinalização de adesão da base consumista aos processos midiáticos novos, as empresas estão sendo forçadas a reordenar seus modelos de negócios de longas décadas, pois precisam lutar para não perder espaço, manter inabalados tanto o lucro quanto participar consistentemente dos novos mercados, preservando intactos os laços com os consumidores. Já os consumidores utilizam as novas tecnologias para ter maior controle e acesso aos conteúdos e poder interagir com outros consumidores. No mundo da abundância tecnológica, os receptores da comunicação parecem mais tranqüilos e satisfeitos que os emissores, que na atualidade têm que correr para fidelizar audiências.

Dessa forma, a participação dos consumidores talvez seja o principal ponto positivo e de destaque na questão da convergência tecnológica. Corroborando com a idéia, Jenkins afirma que "a convergência representa uma mudança no modo como encaramos nossas relações com as mídias" (2008, p. 49). Essas relações foram amplificadas quando a comunicação tornou-se de mão dupla e os consumidores ganharam o poder de falar e serem ouvidos por uma infinidade de pessoas. Agora os "produtores que não conseguirem fazer as pazes com a nova cultura participativa enfrentarão uma clientela declinante e a diminuição dos lucros" (2008, p. 51). Para Jenkins a cultura participativa faz parte da consolidação de um novo paradigma que atua na forma como as novas mídias são exploradas pelos usuários, onde estes passam a exercitar uma postura mais ativa e interativa com conteúdos digitais. Hoje, é preciso que as empresas de comunicação devotem atenção irrestrita ao público, ouçam o que ele está dizendo, pois essa é a maior forma de medir audiência identificando suas preferências e tendências, garantindo a continuidade do processo empresarial.

Um dos maiores exemplos de cultura participativa da web é o YouTube. O maior site de vídeos mundial, nascido em 2005, tem como seu principal negócio agregar vídeos amadores ou profissionais em uma plataforma que estimula os participantes. Um dos fundadores do site garante que o sucesso do YouTube se deve a quatro fatores: recomendações de vídeos, compartilhamento de vídeos por links que podem ser enviados por e-mail, a publicação de vídeos do YouTube em outras páginas da Internet e comentários (BURGEES, GREEN, 2009, p. 19). A cultura participativa descreve a junção das tecnologias acessíveis aos usuários (como por exemplo, sites de redes sociais e sites da internet), o 
conteúdo gerado e manipulado pelos consumidores quando trocam informações pela web e a alteração na relação de poder entre mídia e consumidor, (pois a partir de agora os usuários/consumidores geram opiniões que influenciam outros consumidores tornando-se "poderosos" desta forma). A produção e o compartilhamento de vídeos no YouTube fazem com que as pessoas estabeleçam laços e criem uma nova forma de comunicação que rompe com o modelo de negócios da mídia clássica. O YouTube começa a assumir uma postura considerada mais séria quando se articula com a mídia tradicional para transmitir discursos políticos ou quando passa a ser usado por professores universitários que fazem upload de palestras, aulas e debates (idem).

A infinidade de conteúdos disponibilizados no site por todas as pessoas que dele se utilizam fornece um ambiente propício para seu próprio desenvolvimento. Toda informação disponível na rede pode ser considerada parte do que Jenkins denominou de inteligência coletiva. Esse autor explica que a inteligência coletiva "pode ser vista como uma fonte alternativa de poder midiático", sendo que este poder está sendo usado para o entretenimento, mas em breve será aplicado para fins mais "sérios" (JENKINS, 2008, p. 28). Embora Jenkins acredite que a aplicação desta nova forma de troca de informações possa vir a ser usada seriamente no futuro, atualmente já existem ações que fortalecem o uso desta nova plataforma para fins como consultas públicas de assuntos de interesse público, ações que defendem os animais, grupos que se reúnem na rede e coletam dados para o combate à pedofilia, entre outros. A Internet é um celeiro de novas tendências na área da comunicação, com ela o consumidor está tendo a oportunidade de ser participativo e se sentir do lado do produtor/emissor quando tem atitudes mais ativas com o conteúdo da rede. A transformação desse novo consumidor é um caminho sem volta, o gosto de estar presente e participar se enraíza e dificilmente ele voltará a ser como antes, um mero espectador.

\section{A era do display multimídia interativo}

Com as tecnologias digitais surgem diferentes linguagens e formatos que são consumidos em diversos aparelhos, mas como se pode definir esse intrincado de inovações que impactam no consumo da informação? Jenkins (2008, p. 43) afirma que "estamos entrando em uma era em que haverá mídias em todos os lugares", elas estarão disponíveis em 
tudo, ou melhor, em todo local, na forma de displays audiovisuais .Os aparelhos televisores vendidos atualmente no mercado são como grandes quadros emoldurados (que exibem imagens em alta definição) para se pendurar na parede. As geladeiras, fogões, painel do carro, tudo poderá conter telas conectadas, verdadeiros repositórios de informação e entretenimento.

A palavra display significa em português mostrador ou painel que apresenta em uma tela algum objeto audiovisual sensível ao toque ou não. Segundo Cavallini (2008, p. 124), display é "todo e qualquer tipo de tela, do celular ao monitor de plasma, passando pelos novos papéis eletrônicos e até mesmo projetores inteligentes". Como a tendência da mídia é se tornar totalmente digital considera-se que o conteúdo seja produzido, transmitido e armazenado neste formato. Os displays vêm se tornando extremamente populares e são utilizados em vários produtos, equipamentos e instrumentos como: calculadoras, terminais bancários e de cartões de crédito, painéis informativos e de equipamentos etc. Nesse sentido, Hirakawa e Cugnasca (2007, p.4) argumentam que

essa popularização vem trazendo diversas vantagens, pois possibilita a utilização de um dispositivo de baixo consumo e de fácil programação e interfaceamento com a maioria dos microprocessadores e microcontroladores, a um custo muito reduzido. Atualmente, existem muitos fabricantes que produzem displays de cristal líquido que funcionalmente possuem características semelhantes. As diferenças são quanto a conexão, número de linhas e colunas, dimensões físicas e consumo.

Existe uma infinidade de displays eletrônicos digitais, os mais conhecidos são aqueles de LCD, OLED, plasma e vislumbra-se que no futuro existam displays a laser, de nanotubo de carbono e de nanocristal que cria telas flexíveis e vibrantes. A variedade de tecnologia de telas faz com que a competição entre as empresas seja extremamente acirrada, fazendo com que elas tenham de investir cada vez mais em tecnologia refinadíssima para a produção de telas com alta definição de imagem, passando de high definition ${ }^{14}$ (alta definição) para ultra high definition $^{15}$. Uma empresa dos Emirados Árabes tem um projeto de construir a maior tela de LED do mundo (uma altura de 33 andares) que pode ser vista até um quilômetro e meio de

\footnotetext{
${ }^{14}$ Imagens high definition têm 1080 por 1920 pixels, cerca de dois milhões de pixels.

${ }^{15}$ As imagens ultra high definition são formadas por 4320 linhas de 7680 pixels, cerca de 32 milhões de pixels (SIQUEIRA, 2008, p. 59).
} 
distância ${ }^{16}$. Hoje, a maior tela de LED do mundo está em um shopping em Beijing na China, custou 32 milhões de dólares e tem 25 metros de comprimento e 30 de largura ${ }^{17}$.

De acordo com os sites de empresas como Sony, Toshiba, LG, Samsung, Apple, entre outras, nota-se que estas investem em telas cada vez menores para oferecer, além de qualidade de imagem em aparelhos celulares pequenos, tecnologias que dêem ao usuário a comunicação plena contida na expressão inglesa anyway, anywhere, anytime ${ }^{18}$. Relógios de pulso que exercem a função de telefone, de câmera fotográfica, de player de áudio MP3 e possuem conexão via bluetooth (para conexões sem fio via rede) também já foram lançados com uma tela do tamanho de 1,33 polegadas ${ }^{19}$. Informações dos centros de inovação da indústria revelam que existem pesquisas que pretendem conferir atributos mais sensoriais aos displays tecnológicos, que passam cada vez mais, a integrar o corpo humano, atuando como uma extensão do mesmo, como prognosticava McLuhan. Estão preparando um dispositivo chamado "sense" que pretende reproduzir gostos, aromas e texturas aos usuários das telas. O projeto foi premiado devido à inovação que representa, porém ainda está longe de chegar ao mercado por ser muito futurista e com várias questões técnicas a serem superadas ${ }^{20}$.

Além disso, vários vídeos ${ }^{21}$ futuristas desenvolvidos por designers, empresas de tecnologia, entre outros, apresentaram telas que poderão estar em qualquer lugar (na sala de estar, na porta da geladeira, no celular, no carro, no pulso). Tal recurso oferecerá ao usuário uma experiência inédita envolvendo ação e imersão, assim como fizeram os primeiros aparelhos de videogame, na década de 70, nos Estados Unidos, quando estes eram plugados à tela da TV. Os videogames de hoje são muito mais sofisticados e continuam sendo freneticamente aperfeiçoados para que o usuário tenha cada vez mais a sensação do que

\footnotetext{
${ }^{16}$ Companhia árabe anuncia construção da maior tela do mundo. Disponível em: $<$ http://tecnologia.terra.com.br/interna/0,,OI3236818-EI4799,00-

Companhia+arabe+anuncia+construcao+da+maior+tela+do+mundo.html>. Acesso em: 9 jul. 2010.

${ }^{17}$ Disponível em: <http://www.mundogump.com.br/a-maior-tela-de-led-do-mundo/>. Acesso em: 9 jul. 2010.

${ }^{18}$ De qualquer forma, em qualquer lugar, em qualquer tempo

${ }^{19}$ O chineses atacam novamente: celular de pulso de duas linhas!! Disponível em: <http://cybervida.com.br/ochineses-atacam-novamente-celular-de-pulso-de-duas-linhas>. Acesso em: 9 jul. 2010.

20 JORDÃO, Fábio. Tela permitirá sentir gostos e cheiros por meio do PC. Disponível em: $<$ http://tecnologia.terra.com.br/noticias/0,,OI4555505-EI12882,00-

Tela+permitira+sentir+gostos+e+cheiros+por+meio+do+PC.html>.Acesso em: 11 jul. 2010.

${ }^{21}$ O vídeo “2019 - Uma Visão Do Futuro” é um vídeo produzido pela Microsoft (disponível em: http://www.youtube.com/watch?v=edYOVjqErV0) e apresenta o uso de telas em todos os lugares e ambientes, tudo se transforma em um display. Outro vídeo que tenta prever o futuro dos displays é o "Future of Screen Technology" (disponível em: http://www.youtube.com/watch? $\mathrm{v}=\mathrm{g} 7$ mOdi3O5E) que apresenta telas transparentes e que aumentam de tamanho conforme a necessidade do consumidor.
} 
chamam de realidade aumentada ${ }^{22}$. Foi a partir dos jogos de videogame que as pessoas puderam interagir com o que se apresentava na tela e essa é uma das principais características da nova mídia: a interatividade e a multimídia. Talvez o primeiro antecessor da multimídia tenha sido o cinema ao unir texto e imagem. A multimídia apresenta-se como sendo uma linguagem de interface de textos, gráficos, sons, imagens (2D e 3D), músicas, cinema, animação, vídeo, fotografia etc., todos em formato digital que juntos oferecem ao usuário uma experiência completa de acesso a informações e entretenimento. A multimídia assume cada vez mais a forma de facilitadora e transformadora da vida cotidiana quando modifica a linguagem das mídias alterando a forma como as pessoas recebem conteúdos. A multimídia não evoluiu das mídias tradicionais, mas sim da interatividade e interface existentes nelas. No início dos anos 80, quando a informática evoluía rapidamente e o computador passou a oferecer ícones gráficos e uma interface mais amigável, ao esconder os elementos de programação, a multimídia possibilitou mudanças estruturais na forma de visualizar o conteúdo informático tornando a operação dos computadores mais acessível ao usuário comum (BORGES, 1997). Bairon (1995), em um livro clássico sobre multimídia afirmava que os computadores iriam misturar sons, textos e imagens parecendo mais com espetáculos psicodélicos, tendo prazo de validade curto na indústria informática. Depois, porém percebeu-se que, com a multiplicação de novas interfaces e princípios interativos desenvolvidos, a multimídia ganhara contornos que impactariam na mudança estrutural de tudo que está relacionado à informação.

A multimídia aguça os sentidos humanos quando apresenta interfaces gráficas que se aproximam da realidade como as imagens em 3D. Nos anos 80, quando a multimídia dava seus primeiros passos na eletrônica, foi lançado o filme Tron (1982), de Steven Lisberger. O filme conta a história de um programador de computação e um amigo que vivem uma aventura dentro do software do computador. O interessante do filme foi conhecer o mundo digital a partir de elementos multimidiáticos em escala nanométrica. Outro exemplo foi o filme Viagem Insólita (1987) de Steven Spielberg, que conta a história de um piloto que é miniaturizado dentro de uma nave e injetado dentro do corpo humano. Ele viaja desde o cérebro até o estômago e coração, apresentando assim uma visão de como funciona o corpo humano. Antes, em 1966, o norte-americano Richard Fleischer havia produzido o filme

${ }^{22}$ Termo original em inglês: Augmented reality. 
Viagem fantástica, que então introduzia o tipo de filmes nos quais seres humanos miniaturizados se locomoviam dentro de corpos humanos, observando os órgãos e estando alojados em cápsulas (iguais a submarinos), numa evolução científica sem precedentes.

Os projetos ousados descritos acima só foram possíveis devido à sofisticação dos computadores e da multimídia que possibilitaram a criação de um mundo fantástico e irreal, mas do amplo entendimento e agrado da audiência. Dessa forma, é justo assimilar que a multimídia "não é só determinada pelos caminhos coloridos e interativos das informações, mas, além disso, sua qualidade depende das informações que são colocadas ali” (BAIRON, 1995, p. 34). O que Bairon ressalta é que, além da interface, para que a multimídia seja interessante, é preciso que haja bons conteúdos junto às fantásticas narrativas visuais como, aliás, acontece nos filmes Tron e Viagem Insólita, onde as boas histórias tornaram as experiências de assistir aos mesmos fortemente atrativas.

\section{Considerações}

O que se almejou demonstrar é que quando as tecnologias digitais surgem logo começam a ser desenvolvidas configurações complementares, no sentido de que os diversos meios de comunicação como televisão, internet, rádio, telefone evoluam tecnicamente podendo, cada vez mais, integrarem-se uns com os outros. Além disso, e diferentemente do passado, na atualidade estas são robustamente convergentes e de fácil compreensão de suas lógicas operacionais. Dessa forma, e pelas consistentes e infindáveis evoluções que a arte de disponibilizar conteúdos vem explicitando e, ainda, pela robusta adesão e compreensão de seus pressupostos comunicativos, neste artigo consideramos que o display digital e interativo se configura como a principal base de acesso aos processos informativos da modernidade. Ao que tudo indica, os displays do presente são verdadeiras plataformas interativas em rede e será através deles que as pessoas poderão assistir a conteúdos audiovisuais, fazer ligações, acessar o e-mail, ler notícias, participar de redes sociais, entre outros. Resta-nos lembrar que é preciso continuar a investigar a questão dos recursos audiovisuais que estarão sendo possibilitados nas telas digitais do futuro, pois como essa ferramenta é fortemente envolvente, amigável e sedutora, poderá iludir profundamente os usuários, pois têm convincente potencial para que os seres humanos tenham a sensação de que estão vivamente participando de situações reais, 
quando, de fato, os processos são unicamente virtuais. São recursos tão potentes e que agrupam tamanha capacidade comunicacional que o pesquisador Dênis de Moraes (2001, p. 15) chamou esta convergência de um "macrocampo multimídia, aquela das Infotelecomunicações", onde se somam os aparatos de forma, de conteúdos e de veiculação. São temas de alto interesse que, todavia, serão tratados em outros momentos. Mas que alicerçam nossa investigação, pois esses processos estão disponíveis nas maravilhosas, portáteis e simpáticas telas com pixels cintilantes dos dias atuais. Por isso, no presente trabalho sugerimos que para elas seja mais preciso a adoção da terminologia displays digitais, pois esses aparatos interativos, multiplataformas e plenamente conectados na rede mundial são extremamente úteis e estão presentes na vida cotidiana de expressivo contingente na atualidade. De fato, configuram-se, sobretudo como a base comunicacional que vingará de agora em diante.

\section{REFERÊNCIAS}

BACELAR, Sueli. Campanhas Políticas 2.0 nos EUA: Até Barack Obama. Disponível em: $<$ http://www.suelibacelar.net.br/2010/05/campanhas-politicas-20-nos-eua-ate.html> Acesso em: 16 jul. 2010.

BAIRON, Sérgio. Multimídia. São Paulo: Global Editora, 1995.

BORGES, Roberto. Interface de Sistemas para Navegação em Hiperdocumentos. Porto Alegre: CPGCC da UFRGS, 1997.

BURGESS, Jean, GREEN, Joshua. YouTube e a Revolução Digital: como o maior fenômeno da cultura participativa transformou a mídia e a sociedade. Disponível em:

<http://www.editoraaleph.com.br/site/media/catalog/product/f/i/file_32.pdf >. Acesso em: 14 mai. 2010.

CAVALLINI, Ricardo. O marketing depois de amanhã: explorando novas tecnologias para revolucionar a comunicação. São Paulo: Ed. do Autor, 2008.

FEENBERG, Andrew. What is Philosophy of Technology?. In: CONFERÊNCIA PRONUNCIADA PARA OS ESTUDANTES UNIVERSITÁRIOS DE KOMABA, jun. 2003. Disponível em:

<http://www.sfu.ca/ andrewf/books/What_is_Philosophy_of_Technology.pdf >.

GOLDEMBERG, José. Tecnologia apropriada. Rio de Janeiro: Civilização Brasileira, 1978. 
HIRAKAWA, André, CUGNASCA, Carlos Eduardo. Experiência 4: Interface com teclado e display. 2007. Disponível em: <http://www.pcs.usp.br/ pcs2497/2497e042007.pdf>. Acesso em: 07 jun. 2010.

JENKINS, Henry. Cultura da convergência. São Paulo: Aleph, 2008.

KAHNEY, Leander. A cabeça de Steve Jobs: as lições do líder da empresa mais revolucionária do mundo. Rio de Janeiro: Agir, 2009.

KERCKOVE, Derrick. A pele da cultura. Lisboa: Relógio D’Água Editores, 1995.

MANOVICH, Lev. The language of new media. Massachusetts: The Mit Press, 2000.

MONTEZ, Carlos, BECKER, Valdecir. TV Digital Interativa: Conceitos, desafios e perspectivas para o Brasil. Florianópolis: Editora da UFSC, 2005.

MORAES, Dênis. O concreto e o virtual. Rio de Janeiro: DP\&A, 2001

NEGROPONTE, Nicholas. Vida Digital. São Paulo: Companhia das Letras, 1995.

NOSENGO, Nicola. A extinção dos tecnossaurus. Campinas: Editora Unicamp, 2008.

POOL, Ithiel. Technologies of Freedom. Harvard: Belknap Press, 1983.

SIQUEIRA, Ethevaldo. Para compreender o mundo digital. São Paulo: Globo, 2008.

Original recebido em: 30/10/2012

Aceito para publicação em: 03/12/2012

Resumo sobre o autor

Taís Marina Tellaroli é doutoranda em Comunicação Social pela Universidade Metodista de São Paulo. Bolsista Capes.

Sebastião Carlos Squirra é docente do programa de Pós-graduação em Comunicação da Umesp 